\title{
Does research output cause economic growth or vice versa? Evidence from 34 OECD countries
}

\author{
Hamilton Ntuli ${ }^{1}$, Roula Inglesi-Lotz ${ }^{1,}{ }^{*}$, Tsangyao Chang ${ }^{2}$, Anastassios Pouris ${ }^{3}$ \\ ${ }^{1}$ Department of Economics, University of Pretoria, Pretoria, South Africa. \\ ${ }^{2}$ Department of Finance, Feng Chia University, Taichung, Taiwan. \\ ${ }^{3}$ Institute for Technological Innovation, University of Pretoria, South Africa.
}

*Correspondence to: Roula Inglesi-Lotz roula.inglesi-lotz@up.ac.za.

\begin{abstract}
The causal relation between research and economic growth is of particular importance for political support of science and technology as well as for academic purposes. This paper revisits the causal relationship between research papers published and economic growth in OECD countries for the period 1981-2011, using bootstrap panel causality analysis, which accounts for cross-section dependency and heterogeneity across countries. Our empirical results support unidirectional causality running from research output (in terms of total number of papers published) to economic growth for the US, Finland, Hungary, and Mexico; the opposite causality from economic growth to research papers published for Canada, France, Italy, New Zealand, UK, Austria, Israel, and Poland; and no causality for the rest of the countries. Our findings provide important policy implications for research policies and strategies for OECD countries.
\end{abstract}

\section{Introduction}

Past studies (King, 2004; Vinkler, 2008; Lee et al., 2011) examining the relationship between the growth of an economy measured by the country's gross domestic product (GDP) and the country's research output measured by scientometric indicators have concluded that 
there is some evidence for the existence between them. The scientometric indicators employed may refer to the quantity (number of journal papers) or specific quantity (number of papers per capita) or total impact (total number of citations) and specific impact (citations per paper) of the scientific information published. However, these studies do provide ambiguous conclusions as to the exact direction of causality, i.e. whether GDP promotes research output or vice versa. This difference in the existence and direction of the causality can be attributed to different time periods examined, dissimilar academic and research systems but also as Lee et al. (2011) mention, the different stages in a country's growth and development.

The aim of this paper is therefore to re-investigate the causal relationship between research output and economic growth in OECD countries over the period of 1981-2011 using the bootstrap panel Granger causality test. The paper differs from previous studies in three novel ways. Firstly, we focus solely on the OECD countries. The OECD group consists of quite homogenous economies with similar levels of growth and development - with a few exceptions - however with a variety of socioeconomic characteristics. Secondly unlike previous studies we take into account the possible existence of cross-sectional dependency and heterogeneity across these countries. Ignoring cross-section dependency may lead to serious bias and size distortions (Pesaran, 2006), implying that testing for the cross-section dependence is a necessary step in a panel data analysis. Lastly, by focusing on country-specific analysis, we apply panel causality approach which is able to examine cross-state interrelations and countryspecific heterogeneity. With this approach, possible bias from converting non-stationary variables by differences are avoided since the testing procedure does not require stationary variables.

The rest of the paper is organized as follows. Section 2 briefly discusses local and international literature on the empirical evidence on the relationship between research and economic growth. In section 3 the methodology of the bootstrap panel Granger causality test proposed by Kónya (2006) is presented. Section 4 presents our empirical results and the policy implications of our empirical findings are discussed in the last section. 


\section{Literature review}

The study of the impact of improved skilled human capital on the economic growth and development has not been recently examined in the literature. Romer (1986) found that higher levels of average knowledge stock end up in higher productivity levels. The topic has engaged many researchers conducting more theoretical approaches (Romer, 1986; Lucas, 1988 Tamura, 1991; Schumpeter, 2000) and applied approaches (Price, 1978; Kealey, 1996; De Moya-Anegon and Herrero Solana, 1999; King, 2004; Fedderke, 2005; Fedderke and Schirmer, 2006; Vinkler, 2008; Lee et al., 2011; Shelton and Leydersdorff, 2011; Inglesi-Lotz and Pouris, 2013; InglesiLotz et al. 2013) to show that the accumulation of knowledge is a significant factor to improve the human capital. In a microeconomic sense, the economic productive capacity of a company gets improved by these positive knowledge externalities. On the other side, macroeconomically, an improvement in the quality of the labour through knowledge is advantageous to a country's innovation levels, economic growth and development.

Even though there is great interest in empirical analysis to identify possible consistent causal relationships between scientometric indicators and the GDP, the exact nature of the link has not been clarified so far. Price (1978) and Kealey (1996) in their own separate explorations both found a linear correlation between GDP and scientometric indicators of different countries. De Moya-Anegon and Herrero-Solana (1999) found significant correlation between the GDP of 19 Latin-American countries and the number of their articles in journals referenced by the Science Citation Index (SCI) of the Institute for Scientific Information (ISI) for the period 1991 to 1997. King (2004) examined historical data and found an exponential relationship between number of research articles published and the economic performance for OECD countries for the period 1993 to 2002.

Vinkler (2008) found significant discrepancies in the ratio and relative impact of the journal papers of several scientific fields of some Central and Eastern European countries compared to the European Union member states, the US and Japan. For European Community member states, the US and Japan countries correlation between the GDP and number of publications of a given year proved to be non-significant. Longitudinal studies conducted by Vinkler (2008) showed significant correlations between the yearly values of GDP and number of 
papers published. Studying data referring to consecutive time periods revealed that there is no direct relationship between the GDP and information production of countries. As Vinkler (2008) suggested it may be assumed that grants for Research \& Development (R\&D) do not actually depend on the needs of the market but they differ among countries due to the fact that high income countries can afford spending more rather than low-income countries. Sorenson and Fleming (2004) gave a comprehensive survey of the literature on relations of basic science and technological innovation. Their analysis of the patterns of citations from patents strongly implicates publication as an important mechanism for accelerating the rate of innovation.

Lee et al. (2011) in a recent study used quantitative time series analysis to determine the nature of causal relationships between research output and economic growth for the period 1981 to 2007. The results showed that there is mutual causality between research output and economic growth in developing Asian countries but causality in the developed Western countries was not clear. Lee et al. (2011) emphasized that the most important issues for any nation's science policy are research priorities and the efficiency of R\&D investment and its relation to GDP. These empirical findings had policy significant implications for developing countries when deciding on how to direct their research investment: towards education, infrastructure and engineering, or more towards fundamental science. However, Lee et al. (2011) used single country analyses for 25 observations in a Vector Autoregressive (VAR) framework, and consequently, the results are likely to suffer from small-sample bias due to the small number of available degrees of freedom, unless some bootstrapping procedures were used to obtain critical values for the tests.

Inglesi-Lotz et al. (forthcoming) applied the bootstrap panel Granger causality approach to test the causal link between accumulated knowledge measured as the research performance of the country and proxied by the research papers of a country as a percentage share to the world and economic growth using data from the BRICS countries (i.e., Brazil, Russia, India, China, and South Africa) over the period of 1981-2011. Their results showed no causality for Brazil, Russia, China and South Africa and a positive feedback relationship for India.

Another part of the specific literature conducted single-country analysis. For example, Inglesi-Lotz and Pouris (2013) focused on the South African case for the period 1980 to 2008. 
The authors examined the relationship between research output - measured by the comparative advantage of the country to the rest of the world - and economic growth (GDP) by making use of the ARDL method. The results showed that the comparative performance of the academic research output in South Africa could be considered as a factor affecting the economic growth of the country and the opposite didn't hold. After estimating several different linear regression models for 46 countries around the world, Jin and Jin (2013) found that research publications had positive and significant effects on economic growth for the period 1973 to 2003. However, it should be noted that the findings by Jin and Jin (2013) might overestimate the growth effect of research publications on economic growth due to the omitted variables and a reverse causality from GDP to research publications will be another problem. The endogeneity problem will be mitigated if the direction of causality was well defined.

Table 1 summarises the results of these studies.

Table 1: Results from selected studies

\begin{tabular}{|c|c|c|c|}
\hline Study & Country & Methodology & Results \\
\hline $\begin{array}{l}\text { De Moya-Anegon and } \\
\text { Herrero- Solana (1999) }\end{array}$ & Latin American countries & Indicators analysis & $\begin{array}{l}\text { Research output is directly } \\
\text { proportional to input indicators. }\end{array}$ \\
\hline Vinkler (2008) & $\begin{array}{c}\text { Central and Eastern } \\
\text { European countries, EU, US } \\
\text { and Japan. }\end{array}$ & $\begin{array}{l}\text { Analysis of Mean } \\
\text { Structural Difference }\end{array}$ & $\begin{array}{c}\text { No causality/ correlation for EU, US } \\
\text { and Japan. }\end{array}$ \\
\hline Lee et al. (2011) & $\begin{array}{l}25 \text { developed and } \\
\text { developing countries }\end{array}$ & $\begin{array}{l}\text { Granger causality single } \\
\text { country analysis }\end{array}$ & $\begin{array}{l}\text { No causality in the Western } \\
\text { economies while bidirectional } \\
\text { causality exists for the Asian } \\
\text { countries. }\end{array}$ \\
\hline $\begin{array}{l}\text { Inglesi-Lotz et al. } \\
\text { (forthcoming) }\end{array}$ & BRICS & Panel causality & $\begin{array}{l}\text { No causality in any direction in Brazil, } \\
\text { Russia, China and South Africa but } \\
\text { positive bidirectional relationship in } \\
\text { India for the years 1980-2011 }\end{array}$ \\
\hline $\begin{array}{l}\text { Inglesi-Lotz and Pouris } \\
\text { (2013) }\end{array}$ & South Africa & ARDL & $\begin{array}{l}\text { Research output (\%share to the } \\
\text { world) Granger causes positively } \\
\text { economic growth in } 1980-2008 \text {; no } \\
\text { opposite relationship }\end{array}$ \\
\hline
\end{tabular}

Contrary to these previous empirical papers that examine the relationship between research output and economic growth using data on individual country, we employ here panel Granger causality techniques for a panel of OECD countries. This approach is methodologically superior to single country analysis, particularly when considering the high degree of globalization, 
international trade and financial integration of the OECD countries. An economic shock in one country is likely to affect the other countries and hence, cross-sectional dependency may play important role in detecting causal linkages for OECD countries.

\section{Methodology and data}

Preliminary analysis.

One important issue in a panel causality analysis is to take into account possible crosssection dependence across countries. This is because high degree of globalization, international trade and financial integration make a country to be sensitive to the economic shocks in other countries. Cross-sectional dependency may play important role in detecting causal linkages for OECD countries since these countries are highly integrated.

The second issue to decide before carrying out causality test is to find out whether the slope coefficients are treated as homogenous or heterogeneous to impose causality restrictions on the estimated parameters. As mentioned by Granger (2013), the strong null hypothesis is the causality from one variable to another variable by imposing the joint restriction for the panel. Furthermore, as Breitung (2005) contends the homogeneity assumption for the parameters is not able to capture heterogeneity due to country specific characteristics. In the research papers published and economic growth nexus - as in many economic relationships while there may be a significant relationship in some countries, vice versa may also be true in some other countries.

Taking the above into consideration before we conduct tests for causality, we start with testing for cross-sectional dependency, followed by slope homogeneity across countries. Then, we decide to which panel causality method should be employed to appropriately determine the direction of causality between research papers published and economic growth in OECD countries. In what follows, we outline the essentials of econometric methods used in this study. 


\section{Testing cross-section dependence.}

To test for cross-sectional dependency, the Lagrange multiplier (LM hereafter) test of Breusch and Pagan (1980) has been extensively used in empirical studies. The procedure to compute the LM test requires the estimation of the following panel data model:

$$
y_{i t}=\alpha_{i}+\beta_{i}^{\prime} x_{i t}+u_{i t} \text { for } i=1,2, \ldots, N ; t=1,2, \ldots, T
$$

where $\mathrm{i}$ is the cross section dimension, $\mathrm{t}$ is the time dimension, $x_{i t}$ is $k \times 1$ vector of explanatory variables, $\alpha_{i}$ and $\beta_{i}$ are respectively the individual intercepts and slope coefficients that are allowed to vary across states.

In the LM test, the null hypothesis of no-cross section dependence- $H_{0}: \operatorname{Cov}\left(u_{i t}, u_{j t}\right)=0$ for all $\mathrm{t}$ and $i \neq j_{-}$is tested against the alternative hypothesis of cross-section dependence $H_{1}: \operatorname{Cov}\left(u_{i t}, u_{j t}\right) \neq 0$, for at least one pair of $i \neq j$. In order to test the null hypothesis, Breusch and Pagan (1980) developed the LM test as:

$$
L M=T \sum_{i=1}^{N-1} \sum_{j=i+1}^{N} \hat{\rho}_{i j}^{2}
$$

where $\hat{\rho}_{i j}$ is the sample estimate of the pair-wise correlation of the residuals from Ordinary Least Squares (OLS) estimation of equation (1) for each i.

Under the null hypothesis, the LM statistic has asymptotic chi-square with $N(N-1) / 2$ degrees of freedom. It is important to note that the LM test is valid for $\mathrm{N}$ relatively small and $\mathrm{T}$ sufficiently large.

However, the CD test is subject to decreasing power in certain situations that the population average pair-wise correlations are zero, although the underlying individual population pair-wise correlations are non-zero (Pesaran et al., 2008, p.106). Furthermore, in stationary dynamic panel data models the $C D$ test fails to reject the null hypothesis when the factor loadings have zero mean in the cross-sectional dimension. In order to deal with these problems, Pesaran et 
al. (2008) propose a bias-adjusted test which is a modified version of the LM test by using the exact mean and variance of the LM statistic. The bias-adjusted LM test is:

$$
L M_{a d j}=\sqrt{\left(\frac{2 T}{N(N-1)}\right)} \sum_{i=1}^{N-1} \sum_{j=i+1}^{N} \hat{\rho}_{i j} \frac{(T-k) \rho_{i j}^{2}-\mu_{T i j}}{\sqrt{v_{T i j}^{2}}}
$$

where $\mu_{T i j}$ and $v_{T i j}^{2}$ are respectively the exact mean and variance of $(T-k) \hat{\rho}_{i j}^{2}$, that are provided in Pesaran et al. (2008, p.108). Under the null hypothesis with first $T \rightarrow \infty$ and then $\mathrm{N} \rightarrow \infty, L M_{a d j}$ test is asymptotically distributed as standard normal.

Testing for slope homogeneity.

Second issue in a panel data analysis is to decide whether or not the slope coefficients are homogenous. The causality from one variable to another variable by imposing the joint restriction for whole panel is the strong null hypothesis (Granger, 2013). Moreover, the homogeneity assumption for the parameters is not able to capture heterogeneity due to country specific characteristics (Breitung, 2005).

The most familiar way to test the null hypothesis of slope homogeneity- $H_{0}: \beta_{i}=\beta$ for all iagainst the hypothesis of heterogeneity- $H_{1}: \beta_{i} \neq \beta_{j}$ for a non-zero fraction of pair-wise slopes for $i \neq j_{-}$is to apply the standard $\mathrm{F}$ test. The $\mathrm{F}$ test is valid for cases where the cross section dimension $(\mathrm{N})$ is relatively small and the time dimension $(\mathrm{T})$ of panel is large; the explanatory variables are strictly exogenous; and the error variances are homoscedastic. By relaxing homoscedasticity assumption in the F test, Swamy (1970) developed the slope homogeneity test on the dispersion of individual slope estimates from a suitable pooled estimator. However, both the F and Swamy's test require panel data models where $\mathrm{N}$ is small relative to T. Pesaran and Yamagata (2008) proposed a standardized version of Swamy's test (the so-called $\tilde{\Delta}$ test) for testing slope homogeneity in large panels. The $\tilde{\Delta}$ test is valid as $(N, T) \rightarrow \infty$ without any restrictions on the relative expansion rates of $\mathrm{N}$ and $\mathrm{T}$ when the error terms are normally 
distributed. In the $\tilde{\Delta}$ test approach, first step is to compute the following modified version of the Swamy's test:

$\tilde{S}=\sum_{i=1}^{N}\left(\hat{\beta}_{i}-\tilde{\beta}_{W F E}\right)^{\prime} \frac{x_{i}^{\prime} M_{\tau} x_{i}}{\tilde{\sigma}_{i}^{2}}\left(\hat{\beta}_{i}-\tilde{\beta}_{W F E}\right)$

where $\hat{\beta}_{i}$ is the pooled OLS estimator, $\tilde{\beta}_{W F E}$ is the weighted fixed effect pooled estimator, $M_{\tau}$ is an identity matrix, the $\tilde{\sigma}_{i}^{2}$ is the estimator of $\sigma_{i}^{2} *$ Then the standardized dispersion statistic is developed as:

$$
\tilde{\Delta}=\sqrt{N}\left(\frac{N^{-1} \tilde{S}-k}{\sqrt{2 k}}\right)
$$

Under the null hypothesis with the condition of $(N, T) \rightarrow \infty$ so long as $\sqrt{N} / T \rightarrow \infty$ and the error terms are normally distributed, the $\tilde{\Delta}$ test has asymptotic standard normal distribution. The small sample properties of $\tilde{\Delta}$ test can be improved under the normally distributed errors by using the following bias adjusted version:

$$
\tilde{\Delta}_{a d j}=\sqrt{N}\left(\frac{N^{-1} \tilde{S}-E\left(\tilde{z}_{i t}\right)}{\sqrt{\operatorname{var}\left(\tilde{z}_{i t}\right)}}\right)
$$

where the mean $E\left(\tilde{z}_{i t}\right)=k$ and the variance $\operatorname{var}\left(\tilde{z}_{i t}\right)=2 k(T-k-1) / T+1$.

\section{Panel Causality Test.}

Once the existence of cross-section dependency and heterogeneity across OECD countries is ascertained, we apply a panel causality method that should account for these dynamics. The bootstrap panel causality approach proposed by Kónya (2006) is able to account for both crosssection dependence and country-specific heterogeneity. This approach is based on Seemingly Unrelated Regression (SUR) estimation of the set of equations and the Wald tests with

\footnotetext{
* In order to save space, we refer to Pesaran and Yamagata (2008) for the details of estimators and for Swamy’s test.
} 
individual specific country bootstrap critical values. Since country-specific bootstrap critical values are used, the variables in the system do not need to be stationary, implying that the variables are used in level form irrespectively of their unit root and cointegration properties. Thereby, the bootstrap panel causality approach does not require any pre-testing for panel unit root and cointegration analyses. Besides, by imposing country specific restrictions, we can also identify which and how many states exist in the Granger causal relationship.

The system to be estimated in the bootstrap panel causality approach can be written as:

$$
\begin{aligned}
& y_{1, t}=\alpha_{1,1}+\sum_{i=1}^{l y_{1}} \beta_{1,1, i} y_{1, t-i}+\sum_{i=1}^{l x_{1}} \delta_{1,1, i} x_{1, t-i}+\varepsilon_{1,1, t} \\
& y_{2, t}=\alpha_{1,2}+\sum_{i=1}^{l l_{1}} \beta_{1,2, i} y_{2, t-i}+\sum_{i=1}^{l x_{1}} \delta_{1,2, i} x_{2, t-i}+\varepsilon_{1,2, t} \\
& \vdots \\
& y_{N, t}=\alpha_{1, N}+\sum_{i=1}^{l y_{1}} \beta_{1, N, i} y_{N, t-i}+\sum_{i=1}^{l x_{1}} \delta_{1, N, i} x_{1, N, t-i}+\varepsilon_{1, N, t}
\end{aligned}
$$

and

$$
\begin{aligned}
& x_{1, t}=\alpha_{2,1}+\sum_{i=1}^{l y_{2}} \beta_{2,1, i} y_{1, t-i}+\sum_{i=1}^{l x_{2}} \delta_{2,1, i} x_{1, t-i}+\varepsilon_{2,1, t} \\
& x_{2, t}=\alpha_{2,2}+\sum_{i=1}^{l y_{2}} \beta_{2,2, i} y_{2, t-i}+\sum_{i=1}^{l x_{2}} \delta_{2,2, i} x_{2, t-i}+\varepsilon_{2,2, t} \\
& \vdots \\
& x_{N, t}=\alpha_{2, N}+\sum_{i=1}^{l y_{2}} \beta_{2, N, i} y_{N, t-i}+\sum_{i=1}^{l x_{2}} \delta_{2, N, i} x_{N, t-i}+\varepsilon_{2, N, t}
\end{aligned}
$$

Where $y$ denotes real income, $\mathrm{x}$ refers to research papers published (in terms of total number of papers published), $I$ is the lag length. Since each equation in this system has different predetermined variables while the error terms might be contemporaneously correlated (i.e. cross-sectional dependency), these sets of equations are the SUR system.

In the bootstrap panel causality approach, there are alternative causal linkages for each country in the system that (i) there is one-way Granger causality from $x$ to $y$ if not all $\delta_{1, i}$ are zero, but all 
$\beta_{2, i}$ are zero, (ii) there is one-way Granger causality running from y to $\mathrm{x}$ if all $\delta_{1, \mathrm{i}}$ are zero, but not all $\beta_{2, i}$ are zero, (iii) there is two-way Granger causality between $\mathrm{x}$ and $\mathrm{y}$ if neither $\delta_{1, i}$ nor $\beta_{2, i}$ are zero, and finally (iv) there is no Granger causality in any direction between $\mathrm{x}$ and $\mathrm{y}$ if all $\delta_{1, \mathrm{i}}$ and $\beta_{2, i}$ are zero.

\section{Data}

The annual data used in this study covers the period from 1981 to 2011 for the 34 OECD countries. The variables include total real GDP (RGDP) and research papers published (in terms of total number of papers published). Research papers published is expressed in terms of total number of papers published and data is from National Science Indicators Database of the Institute for Scientific Information (ISI). Thomson Reuters currently indexes over 10,000 journals in the Sciences, Social Sciences, and Arts \& Humanities. In the NSI database the ISI counts articles, notes, reviews and proceeding papers, but not other types of items and journal marginalia such as editorials, letters, corrections, and abstracts (Inglesi-Lotz and Pouris, 2011). Real GDP is measured in constant 2005 U.S. dollars and comes from the World Development Indicators (World Bank, 2012).

\section{Empirical results}

Before we test for causality we first test for both cross-sectional dependency and countryspecific heterogeneity as we believe that OECD countries are highly integrated in their economic relations. To investigate the existence of cross-section dependence we carried out four different tests ( $L M, C D I m, C D, L M a d j)$. Secondly, as indicated by Kónya (2006), the selection of optimal lag structure is of importance because the causality test results may depend critically on the lag structure. In determining lag structure we follow Kónya's approach that maximal lags are allowed to differ across variables, but to be same across equations. We estimate the system for each possible pair of ly1, Ix1, ly2 and Ix2 respectively by assuming from 1 to 4 lags and then choose the combinations which minimize the Schwarz Bayesian Criterion. Thirdly, because 
Bootstrap panel causality test proposed by Kónya (2006) requires T>N, and we have 34 countries with 31 years for each country, therefore, we divide these 34 countries into two groups: A and B based on their GDP of the countries in 2010 (See Table 2).

Table 2. Country classification into two groups based on their GDP in 2010

\begin{tabular}{|c|c|}
\hline GROUP A & GROUP B \\
\hline Australia, Belgium, Canada, France, Germany, Italy, & Austria, Chile, Czech Republic, Denmark, Estonia, \\
Japan, Luxembourg, Netherlands, New Zealand, & Finland, Greece, Hungary, Iceland, Ireland, Israel, \\
Portugal, Spain, Sweden, Switzerland, Turkey, UK, US & $\begin{array}{c}\text { Mexico, Norway, Poland, Slovakia, Slovenia, South } \\
\text { Korea }\end{array}$ \\
\hline
\end{tabular}

Our tests for cross-sectional dependency and heterogeneity are presented in Tables 3 and 4, respectively for group $A$ and group $A$ and group $B$.

Table 3. Cross-sectional Dependence and Homogeneous Tests (Group A)

\begin{tabular}{|l|c|}
\hline$C D_{B P}$ & $1196.005^{* * *}$ \\
\hline$C D_{L M}$ & $64.272^{* * *}$ \\
\hline$C D$ & $30.905^{* * *}$ \\
\hline$L M_{a d j}$ & $187.504^{* * *}$ \\
\hline$\tilde{\Delta}$ & $1043.695^{* * *}$ \\
\hline$\tilde{\Delta}_{a d j}$ & $36.718^{* * *}$ \\
\hline Swamy Shat & $6102.740^{* * *}$ \\
\hline
\end{tabular}

Note: $1 . * *, * *$, and $*$ indicate significance at the $0.01,0.05$, and 0.1 levels, respectively

Table 4. Cross-sectional Dependence and Homogeneous Tests (Group B)

\begin{tabular}{|l|c|}
\hline$C D_{B P}$ & $530.741^{* * *}$ \\
\hline$C D_{L M}$ & $23.935^{* * *}$ \\
\hline$C D$ & $17.146^{* * *}$ \\
\hline$L M_{a d j}$ & $192.403^{* * *}$ \\
\hline$\tilde{\Delta}$ & $546.984^{* * *}$ \\
\hline$\tilde{\Delta}_{a d j}$ & $90.891^{* * *}$ \\
\hline Swamy Shat & $3.190^{* * *}$ \\
\hline
\end{tabular}

Note: $1 . * *, * *$, and $*$ indicate significance at the $0.01,0.05$, and 0.1 levels, respectively. 
The null hypothesis of no cross-sectional dependency and slope heterogeneity across the countries is strongly rejected at the conventional levels of significance. This finding implies that a shock that occurred in group A (and/or group B) OECD countries seems to be transmitted to other countries. Furthermore, the rejection of slope homogeneity implies that the panel causality analysis by imposing homogeneity restriction on the variable of interest results in misleading inferences. In this respect, the panel causality analysis based on estimating a panel vector autoregression and/or panel vector error correction model by means of generalized method of moments and of pooled ordinary least square estimator is not appropriate approach in detecting causal linkages between research papers published and economic growth in the groups A and B of the OECD countries.

The establishment of the existence of cross-sectional dependency and heterogeneity across group A suggests the suitability of the bootstrap panel causality approach. The results of the bootstrap causality tests are presented in Tables 5 and 6 for group A.

Table 5. Research Output does not Granger Cause GDP (Group A)

\begin{tabular}{|c|c|c|c|c|c|}
\hline \multirow{2}{*}{ Country } & coefficient & Wald Statistics & \multicolumn{3}{|c|}{ Bootstrap Critical Value } \\
\cline { 4 - 6 } & & & $10 \%$ & $5 \%$ & $1 \%$ \\
\hline AUSTRALIA & 0.033 & 1.809 & 9.657 & 13.343 & 22.306 \\
\hline BELGIUM & 0.023 & & & & 33.411 \\
\hline CANADA & -0.018 & 5.473 & 14.435 & 20.032 & 46.600 \\
\hline FRANCE & 0.011 & 2.028 & 17.674 & 26.471 & 49.154 \\
\hline GERMANY & 0.009 & 2.257 & 19.780 & 27.196 & 45.688 \\
\hline ITALY & -0.006 & 0.636 & 17.819 & 24.470 & 38.080 \\
\hline JAPAN & 0.017 & 1.375 & 15.646 & 21.149 & 21.241 \\
\hline LUXEMBOURG & -0.004 & 1.077 & 13.679 & 19.737 & 31.155 \\
\hline NETHERLANDS & 0.040 & 3.680 & 9.762 & 14.573 & 40.065 \\
\hline NEW ZEALAND & 0.045 & 15.827 & 17.028 & 25.097 & 34.903 \\
\hline PORTUGAL & -0.002 & 11.585 & 13.069 & 18.326 & 33.815 \\
\hline SPAIN & 0.011 & 0.235 & 13.692 & 18.975 & 48.187 \\
\hline SWEDEN & 0.031 & 4.728 & 20.006 & 29.024 & 47.108 \\
\hline SWITZERLAND & 0.013 & 4.048 & 20.586 & 28.802 & 37.622 \\
\hline TURKEY & 0.033 & 1.505 & 14.084 & 20.359 & 31.430 \\
\hline UK & 0.002 & 4.637 & 10.985 & 17.450 & 40.810 \\
\hline USA & 0.053 & 0.018 & 14.525 & 21.829 & 36.905 \\
\hline
\end{tabular}

Note: $1 . * * * * *$, and $*$ indicate significance at the $0.01,0.05$ and 0.1 levels, respectively.

2. Bootstrap critical values are obtained from 10,000 replications. 
Table 6. GDP does not Granger Cause Research Output (Group A)

\begin{tabular}{|c|c|c|c|c|c|}
\hline \multirow[t]{2}{*}{ Country } & \multirow[t]{2}{*}{ coefficient } & \multirow[t]{2}{*}{ Wald Statistics } & \multicolumn{3}{|c|}{ Bootstrap Critical Value } \\
\hline & & & $10 \%$ & $5 \%$ & $1 \%$ \\
\hline AUSTRALIA & 0.188 & 4.555 & 26.523 & 38.374 & 70.274 \\
\hline BELGIUM & 0.460 & 11.756 & 25.014 & 33.768 & 61.806 \\
\hline CANADA & 0.283 & $19.646 * *$ & 11.335 & 17.684 & 33.058 \\
\hline FRANCE & 0.409 & $22.741 *$ & 22.279 & 33.087 & 56.139 \\
\hline GERMANY & 0.235 & 4.854 & 22.212 & 32.863 & 53.321 \\
\hline ITALY & 0.606 & $25.337^{*}$ & 20.009 & 26.999 & 48.558 \\
\hline JAPAN & 0.296 & 5.350 & 22.412 & 35.836 & 67.152 \\
\hline LUXEMBOURG & 2.809 & 22.117 & 23.291 & 33.427 & 62.953 \\
\hline NETHERLANDS & 0.286 & 14.025 & 14.498 & 23.375 & 37.731 \\
\hline NEW ZEALAND & 1.158 & $21.368^{* *}$ & 10.678 & 16.273 & 31.738 \\
\hline PORTUGAL & 0.717 & 6.113 & 14.077 & 20.087 & 32.454 \\
\hline SPAIN & 0.319 & 8.746 & 12.674 & 18.624 & 29.676 \\
\hline SWEDEN & 0.077 & 1.556 & 12.558 & 18.541 & 34.643 \\
\hline SWITZERLAND & 0.520 & 12.154 & 17.339 & 24.615 & 41.059 \\
\hline TURKEY & 0.151 & 4.482 & 15.936 & 23.129 & 46.595 \\
\hline UK & 0.224 & $27.023 * *$ & 13.918 & 19.407 & 34.395 \\
\hline USA & 0.107 & 0.129 & 19.566 & 29.162 & 65.022 \\
\hline
\end{tabular}

Note: $1 . * * * * *$, and $*$ indicate significance at the $0.01,0.05$ and 0.1 levels, respectively.

2. Bootstrap critical values are obtained from 10,000 replications.

Empirical results support unidirectional causality running from research papers (in terms of total number of papers published) to economic growth for the US only; the opposite causality from economic growth to research papers published for Canada, France, Italy, New Zealand, and the UK; and no causality in any direction between research papers published and economic growth for the rest of 11 countries. In the case of Canada, France, Italy, New Zealand, and the UK; the results show a unidirectional causality running from economic growth to total number of papers published. This indicates that economic growth stimulates research papers published which in their turn, boost economic growth even further in these countries. In contrast, in the US, there was an opposite causality running from research papers published to economic growth meaning that research papers have a certain impact on economic growth, supporting the research-growth hypothesis in the US. Tables 7 and 8 report the results of the bootstrap causality tests across group $B$. 
Table 7. Research Output does not Granger Cause GDP (Group B)

\begin{tabular}{|l|l|c|c|c|c|}
\hline \multirow{2}{*}{ Country } & \multirow{2}{*}{ coefficient } & \multirow{2}{*}{ Wald Statistics } & \multicolumn{3}{|c|}{ Bootstrap Critical Value } \\
\cline { 4 - 6 } & & & $10 \%$ & $5 \%$ & $1 \%$ \\
\hline AUSTRIA & 0.001 & 0.574 & 12.782 & 20.146 & 41.636 \\
\hline CHILE & 0.001 & 0.173 & 11.208 & 17.057 & 26.992 \\
\hline CZECH REPUBLIC & 0.000 & 0.337 & 18.641 & 28.193 & 58.933 \\
\hline DENMARK & 0.004 & 7.914 & 9.981 & 13.441 & 19.364 \\
\hline ESTONIA & 0.006 & 7.843 & 14.165 & 20.528 & 32.921 \\
\hline FINLAND & 0.007 & $\mathbf{3 0 . 2 4 8 * *}$ & 21.131 & 29.034 & 47.475 \\
\hline GREECE & 0.003 & 2.656 & 14.165 & 20.343 & 41.783 \\
\hline HUNGARY & 0.010 & $\mathbf{1 4 . 7 0 1 *}$ & 12.523 & 17.595 & 33.338 \\
\hline ICELAND & 0.001 & 0.542 & 18.228 & 26.538 & 48.071 \\
\hline IRELAND & -0.006 & 5.300 & 10.633 & 15.834 & 27.806 \\
\hline ISRAEL & 0.009 & 3.434 & 15.404 & 22.955 & 40.924 \\
\hline MEXICO & 0.011 & $\mathbf{2 7 . 2 3 8 * *}$ & 11.255 & 18.181 & 30.380 \\
\hline NORWAY & 0.000 & 0.058 & 10.199 & 14.959 & 22.983 \\
\hline POLAND & 0.009 & 15.258 & 20.325 & 28.103 & 53.378 \\
\hline SLOVAKIA & 0.000 & 0.702 & 13.712 & 19.815 & 36.005 \\
\hline SLOVENIA & 0.000 & 0.093 & 19.557 & 28.024 & 66.197 \\
\hline SOUTH KOREA & 0.003 & 2.419 & 10.805 & 14.791 & 27.266 \\
\hline
\end{tabular}

Note: $1 . * * *, * *$, and $*$ indicate significance at the $0.01,0.05$ and 0.1 levels, respectively.

2. Bootstrap critical values are obtained from 10,000 replications.

Table 8. GDP does not Granger Cause Research Output (Group B)

\begin{tabular}{|l|l|c|c|c|c|}
\hline \multirow{2}{*}{ Country } & \multirow{2}{*}{ coefficient } & Wald Statistics & \multicolumn{3}{|c|}{ Bootstrap Critical Value } \\
\cline { 4 - 6 } & & & $10 \%$ & $5 \%$ & $1 \%$ \\
\hline AUSTRIA & 8.260 & $\mathbf{2 6 . 7 5 0 *}$ & 26.628 & 39.041 & 74.661 \\
\hline CHILE & 1.196 & 2.026 & 28.205 & 37.668 & 64.112 \\
\hline CZECH REPUBLIC & 12.105 & 2.102 & 23.298 & 31.570 & 61.442 \\
\hline DENMARK & 0.751 & 0.321 & 23.360 & 33.328 & 59.527 \\
\hline ESTONIA & -0.086 & 0.058 & 13.480 & 20.321 & 36.367 \\
\hline FINLAND & -0.463 & 0.819 & 13.873 & 18.797 & 38.333 \\
\hline GREECE & 2.992 & 4.917 & 13.876 & 21.885 & 43.158 \\
\hline HUNGARY & 1.688 & 3.259 & 13.340 & 20.555 & 36.384 \\
\hline ICELAND & 5.290 & 10.656 & 20.090 & 30.047 & 51.822 \\
\hline IRELAND & 1.194 & 4.435 & 22.172 & 34.819 & 58.271 \\
\hline ISRAEL & 4.609 & $\mathbf{4 0 . 1 5 4 * * *}$ & 12.656 & 19.301 & 38.457 \\
\hline MEXICO & -0.353 & 0.193 & 19.001 & 28.824 & 47.725 \\
\hline NORWAY & 2.860 & 12.482 & 32.746 & 43.837 & 78.319 \\
\hline POLAND & 9.515 & $\mathbf{5 6 . 4 9 3 * * *}$ & 11.696 & 17.264 & 33.623 \\
\hline
\end{tabular}




\begin{tabular}{|l|l|c|c|c|c|}
\hline SLOVAKIA & 1.150 & 0.071 & 24.750 & 32.377 & 61.432 \\
\hline SLOVENIA & -5.233 & 0.262 & 15.201 & 22.861 & 49.009 \\
\hline SOUTH KOREA & 5.254 & 31.318 & 34.198 & 47.162 & 82.235 \\
\hline
\end{tabular}

Note: $1 . * * * * *$, and $*$ indicate significance at the $0.01,0.05$ and 0.1 levels, respectively.

2. Bootstrap critical values are obtained from 10,000 replications.

Empirical results support unidirectional causality running from research output (in terms of total number of papers published) to economic growth for Finland, Hungary, and Mexico; the opposite causality from economic growth to research papers published for Austria, Israel, and Poland; and no causality in any direction between research papers published and economic growth for the rest.

\section{Concluding remarks}

This study applied the bootstrap panel Granger causality approach to examine the causal link between research papers published and economic growth using data from 34 OECD countries over the period of 1981-2011. Our empirical results support unidirectional causality running from research papers (in terms of total number of papers published) to economic growth for the US, Finland, Hungary, and Mexico; the opposite causality from economic growth to research papers published for Canada, France, Italy, New Zealand, UK, Austria, Israel, and Poland; and no causality in any direction between research papers published and economic growth for the rest. The results are summarized in Table 9 below. 
Table 9. Summary of results

\begin{tabular}{|c|c|}
\hline DIRECTION OF CAUSALITY & COUNTRIES \\
\hline Research output Granger causes GDP & US, Finland, Hungary, Mexico \\
\hline GDP Granger causes Research Output & Canada, France, Italy, New Zealand, UK, Austria, Israel, Poland \\
\hline No causality in any direction & $\begin{array}{c}\text { Australia, Belgium, Germany, Japan, Luxembourg, Netherlands, } \\
\text { New Zealand, Portugal, Spain, Sweden, Turkey, Switzerland, } \\
\text { Austria, Chile, Czech Republic, Denmark, Estonia, Greece, Norway, } \\
\text { Slovakia, Slovenia }\end{array}$ \\
\end{tabular}

Similar to other previous studies, what emerges from our empirical findings is that it is difficult to derive any consistent set of results concerning the nexus between research papers published and economic growth in OECD countries with the current available methodologies. As pointed out by Lee et al (2011), OECD countries are highly developed countries and can afford to fund the cost of research. Their research mainly includes fundamental research which is not based on addressing their immediate needs, but that maybe of high value in the future. For these economically advanced nations, innovation becomes a necessity to constantly maintain innovation momentum to sustain competitive advantage (Rai and Lal, 2000). Basic research leads to the development of new methods and instruments that will be useful in future research and development work in both the universities and the companies (Chuang et al, 2010). Newly discovered instruments methods will make considerable contributions to the economy, such as profit, productivity, employment, prosperity, market, and competitiveness. The link between research and economic performance is therefore broken for the majority of these developed nations. Nelson in Pavitt (1991) explains this by the fact that stabilized economies start investing less than the optimum in basic research because the benefits from other expenditures become obvious quicker. As Bornmann (2013) notes: "although the evaluation of research is important when it comes to making investment decisions in research and ensuring the effectiveness of the national innovation system, note that research is, by its very nature, dealing with what we do not know". 
On the other side, a number of countries experience economic growth as a factor to higher research outputs. In these cases, the levels of economic growth and development enable the policy makers to invest more on R\&D and hence, improve the output of the research community.

As a whole, this paper has emphasized the complex relationship between research output and economic growth. Research output presents only one facet of the complex concept of technological progress or innovation that as a whole affects the economies in different ways (Luo et al, In press) but it represents the stock of knowledge in a country. Although investment in fundamental research is at the base of innovation and has a positive impact on economic growth, the decision on whether to invest more on fundamental research or more on applied research rests on the country's development level. Less developed OECD countries should direct their research investment towards applied research to address their immediate needs, whereas higher growth countries should focus on basic research to achieve more innovativeness and to sustain competitive advantage.

Future research in the topic should examine how additional regressors can provide a holistic picture of the research market and its impact to the countries' economies. In addition, research should be conducted on the possible changes of the direction of causality through the years.

\section{References}

Bornmann, L. (2013). What is societal impact of research and how can it be assessed? a literature survey. Journal of the American Society for Information Science and Technology, 64 (2), 217-233.

Breitung, J. (2005). A parametic approach to the estimation of cointegration vectors in panel data. Econometric Reviews 24, 151-173.

Breusch, T.S., Pagan, A.R. (1980). The Lagrange Multiplier test and its applications to model specification in econometrics. The Review of Economic Studies 47(1), 239-253.

Chuang, Y. Lee, L. Hung, W., Lin,P., (2010). Forging into the innovation lead -comparative analysis of scientific capacity. International Journal of Innovation Management, 14(3), 511-529. 
De Moya-Anegon, F. Herrero-Solana, V. (1999). Science in America Latina: A comparison of bibliometric and scientific-technical indicators, Scientometrics 46, 299-320.

Fedderke, J. W. and Schirmer, S. (2006). The R\&D performance of the South African manufacturing sector, 19701983. Economic Change, 39, 125-151.

Fedderke, J.W. (2005). Technology, human capital and growth. University of Cape Town, School of economics. Working paper No 27.

Granger, C.W.J. (2013). Some aspects of causal relationships. Journal of Econometrics 112, 69-71.

Inglesi-Lotz, R. Chang, T. Gupta, R. (2013) Causality between research output and economic growth in BRICS countries. Quality and Quantity. Forthcoming.

Inglesi-Lotz, R. Pouris, A. (2013). The influence of scientific research output of academics on economic growth in South Africa: an autoregressive distributed lag (ARDL) application. Scientometrics 95 (1): 129-139.

Inglesi-Lotz, R., Pouris, A. (2011). Scientometric impact assessment of a research policy instrument: the case of rating researchers on scientific outputs in South Africa. Scientometrics 88, 747-760.

Jin, J.C. Jin, L., (2013). Research publications and economic growth: evidence from cross-country regressions, Applied Economics 45 (8), 983-990.

Kealey, T. (1996). The economic laws of scientific research. New York: St. Martin's Press.

King, D.A. (2004). The scientific impact of nations. What different countries get for their research spending. Nature 430, 311-316.

Kónya, L. (2006). Exports and growth: granger causality analysis on OECD countries with a panel data approach. Economic Modelling 23, 978-992.

Lee, L.-C., Lin, P.H., Chuang, Y.-W. Lee, Y.-Y. (2011). Research output and economic productivity: a Granger causality test. Scientometrics $89,465-478$.

Lucas, R. E. (1988). On the mechanics of economic development. Journal of Monetary Economics, $22,3-42$.

Luo, J., Olechowski, A.L., Magee, C.L. (In Press). Technology-based design and sustainable economic growth. Technovation In Press, Corrected proof.

Pavitt, K. (1991). What makes basic research economically useful. Research Policy 20, 109-119.

Pesaran, M.-H. (2006). Estimation and Inference in Large Heterogeneous Panels with Multifactor Error Structure. Econometrica 74 (4), 967-1012.

Pesaran, M.H. Yamagata, T. (2008). Testing slope homogeneity in large panels. Journal of Econometrics 142, 50-93. 
Price, D.S. (1978). Toward a model for science indicators. In Y. Elkana, G. J. Lederber, R. K. Merton, A. Thackray, \& H. Zuckerman (Eds.), Toward a metric of science: the advent of science indicators. New York: Wiley.

Rai, L.P., Lal, K. (2000). Indicators of the information revolution. Technology in Society 22, 221-235.

Romer, P. M. (1986). Increasing returns and long-run growth. Journal of Political Economy, 94, 1002-1037.

Schumpeter, J.A. (2000). Entrepreneurship as innovation. Entrepreneurship: The social science view 51-75.

Shelton, R.D. \& Leydesdorff, L. (2011). Bibliometric Evidence for Funding Trade-Offs in National Funding Strategies, 13th International Conference on Scientometrics and Informetrics, Durban, July. 2011. Available at http://itri2.org/s/

Sorenson, O. Fleming, L.(2004) Science and the diffusion of knowledge, Research Policy 33, 1615-1634.

Svensson, R. (2008). Growth through Research and Development, What does the Research Literature Say?, Stockholm: Vinnova.

Swamy, P.A.V.B. (1970). Efficient inference in a random coefficient regression model. Econometrica 38, 311-323.

Tamura, R.F. (1991). Fertility, human capital and the "Wealth of Nations". University of lowa, Department of Economics. Working paper No 91-17.

Vinkler, P. (2008). Correlation between the structure of scientific research, scientometric indicators and GDP in EU and non-EU countries. Scientometrics 74, 237-254.

World Bank (2012). World Development Indicators. World Bank, Washington; USA. 